\title{
Impact on Fertilization Rate Using Diluted Hyalase
}

\author{
Chandan $\mathrm{N}^{1 *}$, Reeta Janet Jessy $\mathrm{I}^{\mathbf{2}}$ and Saleem $\mathrm{M}^{3}$ \\ ${ }^{1}$ Department of Health, India \\ ${ }^{2}$ Department of Zoology, Bharathiyar University, Coimbatore, India \\ ${ }^{3}$ Department of Chemistry, University of Madras, India \\ *Corresponding Author: Chandan N, Department of Health, India.
}

\author{
Received: April 23, 2020 \\ Published: May 29, 2020 \\ (C) All rights are reserved by Chandan N., \\ et al.
}

\section{Introduction}

The groundbreaking of Intra cytoplasmic Injection has been announced as one of the major breakthroughs in the field of Assisted Reproductive Medicine. This technique has been utilized as an effective tool to treat infertility and to overcome fertilization failure. ICSI with aggregation with in-vitro Fertilization resulting in birth over five million babies. Yet even with ICSI procedure, some couples fail to fertilize.

Denudation of oocytes includes both enzymatic and mechanical removal of the cumulus cell surrounding the oocytes. Denudation is mandatory in order to make possible visualize the first polar body for precise alignment of oocyte prior to sperm injection. Removal of Cumulus cells in oocyte with hyaluronidase did not interfere with the fertilization rate, embryo development nor pregnancy [1-4].

\section{Objective of the Study}

The follicular fluid is screened in order to collect the oocytes. Each oocyte is surrounded by cumulus-corona- oocyte complex. It is composed of cumulus granulosa cells surrounded in a bed of long hyaluronan oligosaccharide chains cross linked by a complex of hyaluronan binding cell surface and extracellular matrix proteins and proteoglycans. The COCC is removed prior to ICSI in order to gain visual of oocyte grade and first polar body. Conventionally, this has been attained using enzymatic breakdown of substance with hyaluronidase, followed by mechanical denudation of the oocyte with the pipette.
Exposure of COCC in hyaluronidase affect the oocyte quality, comprising artificial interruption of COCC depending on exposure length of oocyte complex in hyaluronidase and the concentration of hyaluronidase.

\section{Hypothesis}

This hypothetical study based on the results of diluted concentration of hyaluronidase used for denudation of oocytes for women undergoing treatment for assisted reproduction by ICSI and their fertilization rate. There is increase in fertilization rate while diluting the hyaluronidase with fertilization media.

\section{Materials and Methods}

Surelife Hyaluronidase (SL- HYS- 1) is ready to use. This is HEPES based fertilization medium added with 80IU of hyaluronidase. The product contains Fertilization medium, hyaluronidase, Human serum albumin, HEPES of pharmaceutical grade. HSA has been tested negative for HbsAg, Anti- HCV, Anti- HIV 1/-HIV 2 and CJD. Surelife Hyaluronidase has made known to be safe and effective in removal of cumulus cells in the human oocyte prior to ICSI.

Surelife Hyaluronidase is HEPES buffered and $\mathrm{pH}$ stable for use outside the incubator without former equilibration. Take 80\% (800 $\mu \mathrm{l})$ of Fertilization media and 20\% (200 $\mu \mathrm{l})$ of Hyaluronidase in a center-well dish. Warm to $37^{\circ} \mathrm{C}$ about 30 minutes prior denudation. The cumulus oocyte complex were incubated in $6 \% \mathrm{CO}_{2}$ at $37^{\circ} \mathrm{C}$ for 2 hours. It is recommended to expose cumulus oocyte complex to hyaluronidase solution for about 60 seconds or until the cumulus is

Citation: Chandan N., et al. “Impact on Fertilization Rate Using Diluted Hyalase”. Acta Scientific Women's Health 2.6 (2020): 11-12. 
separated from the oocytes by drawing them in and out of the glass capillary pipette.

Total 100 oocytes denudation was performed with 20\% dilution form as study 1 and ready to use hylase medium as study 2 . Both the studies denudation was done with the upper limit of $60 \mathrm{sec}$ to the max. After 2 hrs of incubation period oocytes were injected with sperm by ICSI (Intra cytoplasmic sperm injection) technique. After 14 to 16 hrs the oocytes were evaluated for fertilization and compared both fertilization ration.

In study 1 , out of 100 oocytes 83 were fertilized and in study 2, out of 100 oocytes 87 were fertilized having fertilization ration of $83 \%$ and $87 \%$ respectively.

\section{Result}

The diluted hyaluronidase showed better results in fertilization rates. This study exhibits that the use of diluted hylase enzyme, according to the following protocol is favorable and can be successfully used for oocyte denudation and its cost effective strategic to the laboratory.

\section{Conclusion}

To conclude, using $20 \%$ of diluted hylase from ready to use hylase gives better fertilization rate. This reduces stress to the oocytes during denudation process which favours better fertilization.

\section{Bibliography}

1. Devroey P., et al. "Current Theory and Practice of ICSI". Oxford, UK: Published for the European Society for Human Reproduction and Embryology by Oxford University Press (1998).

2. Johnson Lauren NC., et al. "Does intracytoplasmic sperm injection improve the fertilization rate and decrease the total fertilization failure rate in couples with well-defined unexplained infertility? A systematic review and meta-analysis". Fertility and Sterility 100.3 (2013): 704-711.

3. Magier S., et al. "Significance of cumulus oophorus in in-vitro fertilization and oocyte viability and fertility". Human Reproduction 5.7 (1990): 847-852.

4. Manual of Assisted Reproductive Technologies and Clinical Embryology edited by Lt Col Pankaj Talwar VSM.

\section{Assets from publication with us}

- Prompt Acknowledgement after receiving the article

- Thorough Double blinded peer review

- Rapid Publication

- Issue of Publication Certificate

- High visibility of your Published work

Website: www.actascientific.com/

Submit Article: www.actascientific.com/submission.php

Email us: editor@actascientific.com

Contact us: +919182824667

Citation: Chandan N., et al. "Impact on Fertilization Rate Using Diluted Hyalase”. Acta Scientific Women's Health 2.6 (2020): 11-12. 